\title{
Distance learning in antimicrobial stewardship: innovation in medical education
}

\author{
Michel Laks ${ }^{*}$ (D), Carla Morales Guerra, João Luiz Miraglia and Eduardo Alexandrino Medeiros
}

\begin{abstract}
Background: This study aimed to analyse the impact that web-based distance learning has on knowledge gain in medical students, as well as student perceptions of the methodology.

Methods: This was an educational intervention study conducted at a tertiary teaching hospital in the city of São Paulo, Brazil. From 2008 to 2014, we offered a free web-based distance learning course, covering antimicrobial use and microbial resistance, to fifth-year medical students. The course encompassed $100 \mathrm{~h}$ of activities, with five theoretical modules, exercises and simulations, within a virtual learning environment. The students were tutored in their online activities, and some classes were conducted in real time for live discussions. In addition, students underwent face-to-face assessments of their knowledge of the topic before and after the course. Statistical analysis was performed and the means of the overall scores were obtained, as were the respective $95 \%$ confidence intervals (Cls). The means were compared by two-tailed paired t-tests and by the paired Wilcoxon test.
\end{abstract}

Results: Of 814 eligible medical students, 606 (74.45\%) completed the entire course during the study period. The mean score for knowledge of the topic was significantly higher on the final assessment than on the initial assessment $(p<0.001)$. We found that dedication (in hours) was directly proportional to the level of participation, as reflected in the mean final score $(p=0.009)$ and in the proportion of students who passed $(p=0.028)$. All of the participants considered their knowledge adequate or insufficient before the course, stating that it is quite important or important to address the topic during medical education. Although dedication levels were low, 70.5\% stated that they had learned "quite a lot" or "more than expected" about the topic and would dedicate more time to it if they could.

Conclusions: The use of a virtual learning environment can promote teaching and learning in the infectious diseases field, specifically for antimicrobial stewardship, increasing knowledge significantly, and should be considered for inclusion in the final stages of medical education.

Keywords: Antimicrobial stewardship, Distance education, Medicine education

\section{Background}

Over the years, the field of teaching has involved various approaches and different methodologies, evolving from a rigid structure with passive methods to a permissive scenario with active methods that are more constructive [1]. The difficulty of incorporating new knowledge into an already saturated pedagogical plan in a medicine course has prompted a search for new methodologies, as

\footnotetext{
* Correspondence: ohlakse@yahoo.com.br

Infectious Diseases Division, Department of Internal Medicine, Escola Paulista de Medicina, Universidade Federal de São Paulo, Napoleão de Barros, 690, second floor, São Paulo, Brazil
}

well as the use of innovations in information and communication technologies [2]. Among the tools used, the Modular Object-Oriented Dynamic Learning Environment (Moodle) platform, a collaborative virtual learning environment (VLE), is increasingly more widely used by international health promotion agencies and educational institutions, especially in programmes that encompass the topic of antimicrobial therapy. The importance of the topic stems from the fact that antimicrobial agents affect not only the individual but also the environment, altering the sensitivity profiles of bacteria and causing the emergence of antimicrobial resistance. In the twenty-first 
century, antimicrobial resistance has had a significant impact on the quality of health care and on patient safety. That, combined with a rapidly dwindling antimicrobial armamentarium, has resulted in a critical threat to public health worldwide, especially in developing countries such as Brazil.

Antimicrobial stewardship refers to coordinated interventions designed to quantify and improve the appropriate use of antimicrobial agents, promoting the selection of the optimal antimicrobial drug regimen, dose, duration of therapy and route of administration. Antimicrobial stewards seek to achieve optimal clinical outcomes related to antimicrobial use; minimise toxicity and adverse events; reduce the costs of health care for infections; and limit the selection of antimicrobial resistant strains.

Antimicrobial stewardship programmes optimise antimicrobial use to achieve the best clinical outcomes minimising adverse events and limiting selective pressures that drive the emergence of resistance, as well as reducing the costs attributable to suboptimal use of antimicrobial agents. Therefore, antimicrobial stewardship is a fiduciary responsibility for all healthcare facilities across the continuum of care, making it essential that initiatives for its instruction be implemented.

To date, there have been few reports of the experiences of medical schools in assessing knowledge gains related to the use of methodologies such as VLEs in topics within the field of infectious diseases. At most medical schools in Brazil, the pedagogical plan does not include addressing the problem of microbial resistance or the techniques of antimicrobial stewardship. The use of a VLE can fill that gap and could provide a benefit to the health care system when medical graduates begin their professional practice. The objective of this study was to analyse the incorporation of a distance learning environment (DLE) for antimicrobial use and the prevention of antimicrobial resistance into the curriculum of one of the largest medical schools in Latin America and to evaluate its impact on the acquisition of knowledge about the subject, as well as to collect student perceptions of the methodology.

\section{Methods}

We conducted this study under the auspices of the Hospital Epidemiology Committee in the Infectious Diseases Division of the Department of Medicine of the Escola Paulista de Medicina/Universidade Federal de São Paulo (EPM/Unifesp, Federal University of São Paulo Paulista School of Medicine). The EPM/Unifesp operates the Hospital São Paulo, a tertiary care facility with 740 beds, as a venue for the practical activities of medical students, in the city of São Paulo, which is the capital of the state of São Paulo, the most populous state in Brazil. [3] Approximately 730 medical students are currently enrolled in the EPM/Unifesp, which has an average annual enrolment of 121 students, selected through one of the most competitive college entrance examinations in the country. Unifesp is one of the main universities in Brazil, as reflected in the national and major international university rankings [4-6].

This was an educational intervention study in which we developed and implemented a Moodle-based distance learning course on the use of antimicrobial agents and the prevention of antimicrobial resistance. We evaluated the course over seven consecutive years (2008-2014). In the first year of the study (2008), fifth- and sixth-year medical students (those in their next-to-last and last years of medical school, respectively) took the course, whereas we offered it only to fifth-year students thereafter. The study was conducted in four phases: development of the theoretical content and virtual interfaces; application of the course; data collection and analysis of the performance and impressions of the participating students; and statistical analysis of the results obtained.

The course was offered to students via e-mail and through the use of posters placed around the university campus. It was specified that it was an extra-curricular (not-for-credit) course. The students took the course on a voluntary basis, and all participating students gave written informed consent. The questionnaires were made available online, and the responses were kept confidential. Participant privacy was maintained during and after the study period, the data being used exclusively for the purposes of the study. The study was approved by the Research Ethics Committee of the Hospital São Paulo (Protocol no. 429,036).

We used content previously produced for an antimicrobial stewardship/antimicrobial resistance prevention DLE that employed a Moodle-based VLE and was offered to health care professionals [7,8]. Within that context, the theoretical content was made available via a user-friendly interface, as were the links to the collaborative activities. This process of development and application of the course was carried out by tutors throughout the year, approximately $54 \mathrm{~h}$ of development activities and $30 \mathrm{~h}$ of activities being employed in its application. Those activities included monitoring student logs in real time, the tutors encouraging the students to face the problems, resolve questions and make the correct clinical decision. In each year of the study, three face-to-face meetings were held in order to discuss the course with the participants. The course was programmed for $100 \mathrm{~h}$ of activities-including theoretical foundations (the only part of the course that was publicly accessible), on-line exercises/simulations and in-person activities and was composed of five modules. Module 1 presented the antimicrobial agents and concepts related to their use in general, as well as to each antimicrobial class, each 
antimicrobial agent being described in terms of their pharmacological characteristics, mechanisms of action, clinical indications, dosages and adverse reactions. Module 2 presented the main mechanisms of antimicrobial resistance developed by bacteria. Module 3 helped the students correctly interpret microbiology data, which are essential in clinical practice. Module 4 presented the main community-based and health care-associated infections, as well as their treatment. Finally, Module 5 listed the main measures to prevent and control infection with antimicrobial-resistant microorganisms. In addition to the theoretical content, each module included interactive simulations of clinical cases, in which each student received feedback on the alternative selected; a forum for discussion and clarification of questions; and a questionnaire on the content studied.

There were two forms of evaluation. First, a written questionnaire, devised by the tutors and based on the course content, was applied to evaluate participant knowledge before the beginning of the course ("initial face-to-face assessment"), and, after the students had been monitored throughout the course under a tutelage system, the written questionnaire was again applied ("final face-to-face assessment"). The results of the initial and final face-to-face assessments were compared by statistical methods in order to assess the knowledge gained by the students. The second form of evaluation was the application of questionnaires related to each VLE module. In both forms of evaluation, the theoretical concepts of all five modules were addressed, as were aspects related to their clinical application; a passing score was defined as $\geq 7$ (out of 10). All of the data collected were stored in databases.

\section{Statistical analysis}

We calculated the proportion of students who completed the initial and final assessments, that of those who completed only the initial assessment and that of those who completed neither. Additional analyses included only the students who completed both assessments.

The normality of the distribution of the initial and final assessment scores, collectively, was assessed using the Mann-Whitney test for Skewness and Kurtosis. All analyses of the score dataset were carried out in two phases: including and excluding the sixth-year students, who took part only in 2008. The means of the overall scores were obtained, as were the respective $95 \%$ confidence intervals (CIs). The means were compared by two-tailed paired $t$-tests.

The proportional distributions of the responses to questions related to prior antimicrobial knowledge (initial assessment questions) and to evaluation of the course (final assessment questions) were determined for the sample as a whole. Bar graphs were created to illustrate those distributions. Statistical analysis was performed with the Stata statistical software package, version 10.1 (StataCorp LP; College Station, TX, USA).

\section{Results}

The total numbers and proportions of students who enrolled in the course, of those who enrolled and attended the initial assessment but did not engage in the VLE activities, of those who enrolled but did not attend the initial assessment or engage in the VLE activities and of those who completed the course are shown in Table 1, by year. Between 2008 and 2014, a total of 606 students completed the course: 72 were sixth-year students $(2008$ only); and 534 were fifth-year students (2008-2014). Beginning in 2013, there was a downward trend in the number of students enrolled in the course, as well as in the proportion of students who completed it.

The overall (initial plus final assessment) mean scores, with and without the scores of the sixth-year students, are shown in Table 2. The means for the datasets including and excluding the scores of the sixth-year students were virtually identical. The paired $t$-test showed that the mean score was significantly higher in the final assessment than in the initial assessment $(p<0.001$ for both tests). A qualitative analysis of these evaluations allows us to affirm that the students had greater difficulty in answering the questions related to Modules 1, 3 and 4. However, because the tests are not standardized, it is not possible to attribute that greater difficulty exclusively to the difficulty of the specific theme of a given Module. Notably, Modules 1 and 4 were those that attracted the most attention from the participants, perhaps due to the high clinical applicability of the concepts presented therein.

The mean scores of the sixth-year students were significantly higher (with no overlap in the $95 \%$ CIs) than were those of the fifth-year students who took the course in the same year (2008), not only in the initial assessment $(6.02$ vs. $5.54 ; p<0.001)$ but also in the final assessment ( 8.40 vs. $7.77 ; p=0.002$ ).

The proportion of students who had a passing grade was significantly higher in the final assessment than in the initial assessment, whether or not the grades of the sixth-year students were included ( $p<0.001$ for both). The difference between the two was considerable: $10.9 \%$ (with or without the grades of the sixth-year students) in the initial assessment, compared with 86.6 and $87.6 \%$ (with and without the grades of the sixth-year students, respectively) in the final assessment. Analysing the years collectively, we found that dropping out was a major cause of failure to pass the course, accounting for $25.55 \%$ of the failures.

On average, the students with a higher self-reported level of participation scored higher on the final assessment $(8.75$; 95\% CI: 8.59-8.91) than did those reporting 
Table 1 Enrolment and participation in the EPM/Unifesp antimicrobial stewardship course, 2008-2014

\begin{tabular}{|c|c|c|c|c|}
\hline \multirow[t]{3}{*}{ Year* } & \multirow{3}{*}{$\begin{array}{l}\text { Enrolled } \\
N\end{array}$} & \multicolumn{3}{|l|}{ Participation } \\
\hline & & Full (completed) & Initial assessment only & None \\
\hline & & $n(\%)$ & $n(\%)$ & $n(\%)$ \\
\hline \multicolumn{5}{|l|}{2008} \\
\hline Fifth-year students & 108 & $90(83.3)$ & $18(16.7)$ & 0 \\
\hline Sixth-year students & 72 & $72(100.0)$ & 0 & 0 \\
\hline 2009 & 123 & 118 (95.6) & $5(4.0)$ & 0 \\
\hline 2010 & 117 & $116(99.1)$ & $1(0.9)$ & 0 \\
\hline 2011 & 117 & $93(79.5)$ & $21(18.0)$ & $3(2.5)$ \\
\hline 2012 & 129 & $73(56.6)$ & $31(24.0)$ & $25(19.4)$ \\
\hline 2013 & 85 & $19(22.4)$ & $66(77.6)$ & 0 \\
\hline 2014 & 63 & 25 (39.7) & $37(58.7)$ & $1(1.6)$ \\
\hline
\end{tabular}

*Except where otherwise indicated, all enrollees were fifth-year medical students

a lower level of participation (8.48; 95\% CI: 8.34-8.61), and the difference was statistically significant $(t$-test, $p=$ 0.009 ). The proportion of students with a passing grade in the final assessment was also significantly higher among those reporting a higher level of participation (94.8\%; 95\% CI: $89.1-98.1$ vs. $87.1 \%$; $95 \%$ CI: $81.8-91.4$, $p=0.028)$. Although the $95 \%$ CIs overlapped slightly in both cases, the hypothesis tests showed that the differences were statistically significant.

Figure 1 shows the proportional distribution of responses on the initial self-report assessment of student knowledge about antimicrobial agents. None of the students initially categorised their knowledge of antimicrobial agents as very good or even good, and approximately two thirds had received their last formal update on the topic more than one year prior.

Figure 2 shows the proportional distribution of responses on the final self-report assessment, in which the students evaluated the course, quantified the time they had dedicated to it, and qualified their participation in it. Approximately two thirds of the students reported that the course represented their first interaction with a VLE, and $556(91.8 \%)$ stated that they would want to take another course organised by the Infectious Diseases Division of the EPM/Unifesp Department of Medicine. Regarding the topic of the course, 567 (93.6\%) of the students considered the "rational use of antimicrobial agents" important enough to be included in the medical curriculum. In their evaluation of the course content,
$534(88.1 \%)$ of the students found it to be appropriate, whereas $63(10.4 \%)$ considered it to be too specific for a medical school course. In addition, 421 (69.5\%) classified themselves as satisfied or very satisfied with the course, whereas 183 (30.2\%) expressed some degree of dissatisfaction. In their evaluation of the knowledge gain resulting from the course, $421(69.5 \%)$ of the students reported that they had learned a lot or more than they had expected about the topic. The time dedicated to the course was also evaluated: Approximately half of the participants estimated that, between online and face-toface activities, they had dedicated $10-20 \mathrm{~h}$ to the course, whereas $5.80 \%$ reported that they had dedicated more than $50 \mathrm{~h}$ to it. From the analysis of the student logs, we inferred that the level of interest in the activities proposed in the VLE was similar for each type of activity (e.g., real time discussions and online simulations). Of the 606 students who completed the course, 215 (35.4\%) qualified the level of their participation as full or sufficient. In addition, 516 students (85.1\%) stated that they would have dedicated more time to the course if they had been able to.

\section{Discussion}

Fifth-year medical students were offered a course, based on a DLE strategy, on the use of antimicrobial agents and the prevention of microbial resistance. The objective of this study was to determine whether there was a quantitative knowledge gain and thus whether this

Table 2 Mean scores in the initial and final assessments, 2008-2014

\begin{tabular}{lcccc}
\hline Sample & $N$ & $\begin{array}{l}\text { Initial assessment } \\
\text { Mean }(95 \% \mathrm{Cl})\end{array}$ & $\begin{array}{l}\text { Final assessment } \\
\text { Mean }(95 \% \mathrm{Cl})\end{array}$ \\
\hline All students & 606 & $5.78(5.70-5.86)$ & $8.45(8.36-8.53)$ & $<0.001$ \\
All fifth-year students & 534 & $5.75(5.66-5.83)$ & $8.46(8.37-8.54)$ & $<0.001$ \\
\hline
\end{tabular}

"Two-tailed paired $t$-test 


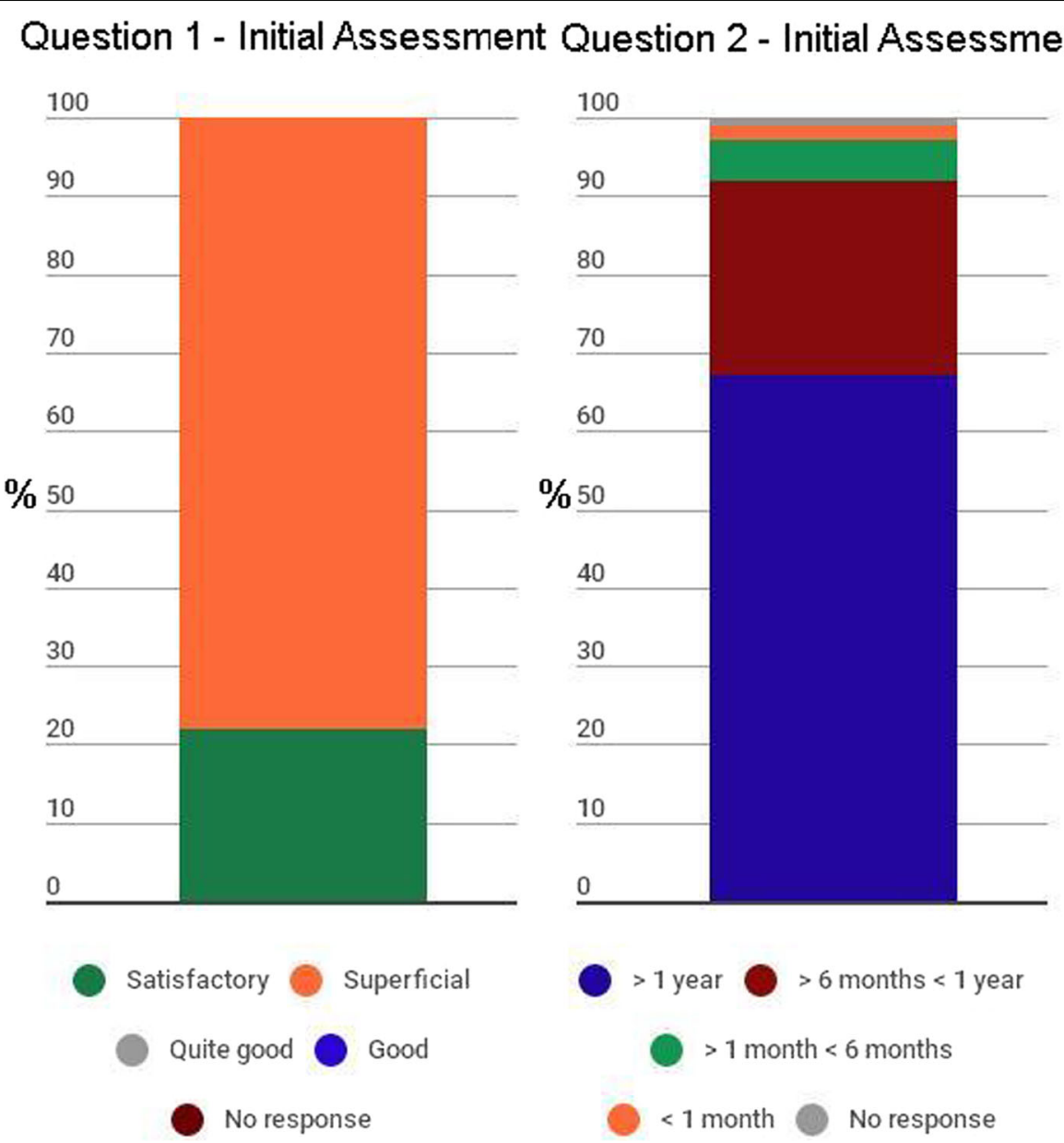

Fig. 1 Proportional distribution of responses to questions 1 and 2 on the initial assessment, 2009-2014. Legend: Question 1: How would you classify your knowledge of antimicrobial agents?; Question 2: When was your last formal update (course, lecture or bibliographic search) on the topic of antimicrobial agents?

teaching modality can be considered valid. To encourage students to engage with the topic, the course was in compliance with the Unifesp institutional guidelines.

Beginning in 2013, there was a downward trend in the number of students enrolled in the course, as well as in the proportion of students who completed the course. This trend might be due to the formula and presentation becoming played out. To remedy that situation, the content was reformulated and the course was validated as an elective course, students who completed the course earning credits. Those measures also have been sufficient to increase the number of students enrolling in the course since 2015.

The fact that the mean final scores were significantly higher than the mean initial scores supports the main hypothesis of the study. Our finding that dropping out was a major cause of failure to pass the course corroborates data from the 2014 Brazilian DLE Census [9]. We believe that the causes of dropout in the present study were similar to those previously reported in the literature [10], such as a lack of time to study or participate in the course due to other curricular or extra-curricular activities.

Our results, like those of other studies of distance learning initiatives in the field of infectious diseases [11], are indicative of validity and the favourable cost-benefit ratio of the method. More than being just an option, a DLE can represent the only applicable methodology or the one that has the most favourable cost-benefit ratio, especially in resource-poor locales or in those that are far from educational centres (for example, a university with distant campuses, where there is a need to deliver unique content), making it an interesting alternative [12-19].

As previously mentioned, a portion of the students expressed some degree of dissatisfaction with the course, and some adjustments therefore needed to be made. The reported reasons are in agreement with the findings of other studies of such initiatives $[9,20]$. One adjustment that could be made is the optimisation of the relationship between the volume of content and the time allotted, as suggested by Premkumar et al. [20] However, as 

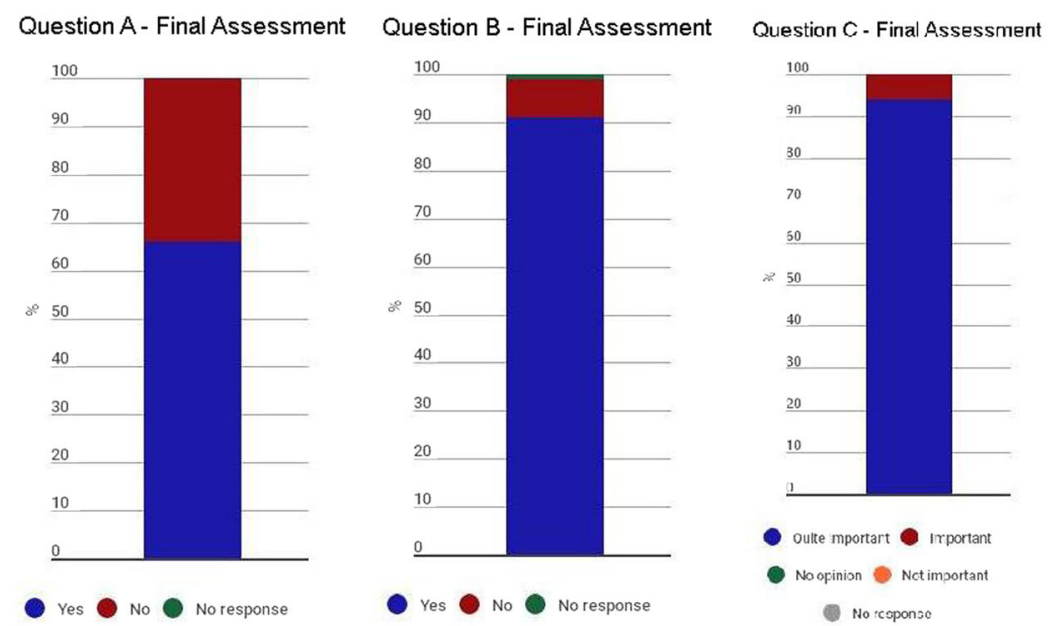

Question D - Final Assessment Question E - Final Assessment

Question F - Final Assessment
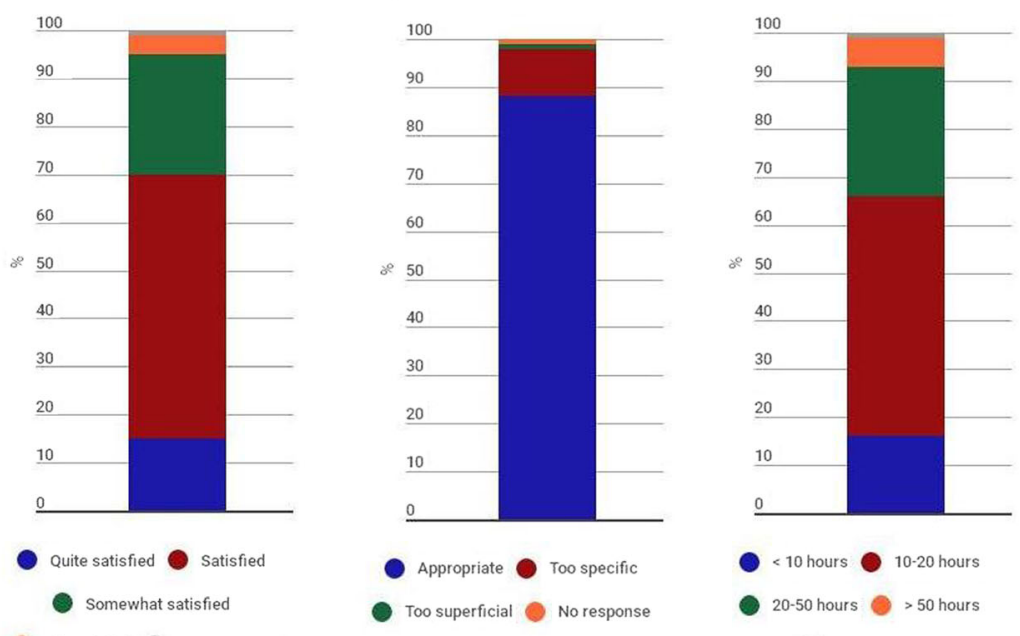

Dissatisfied No response

Too superficial No response

$$
\text { No response }
$$

Question G - Final Assessment

Question H - Final Assessment

\section{Question I - Final Assessment}
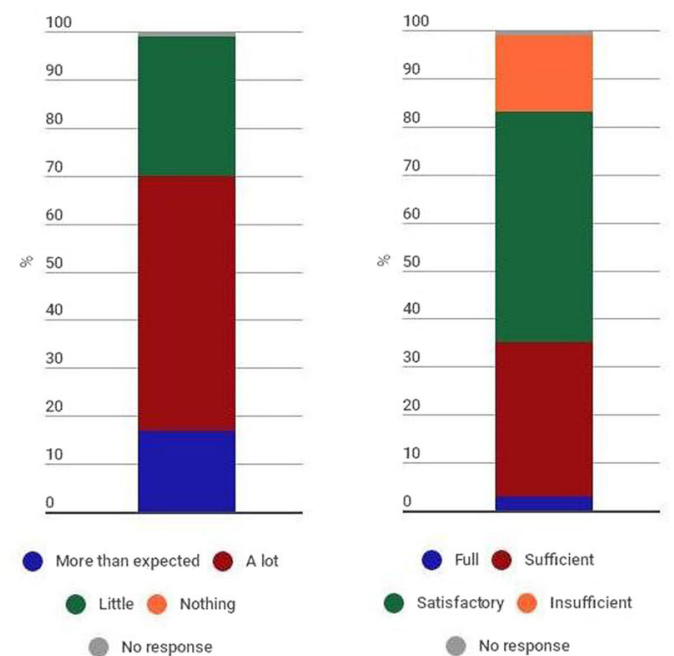

Satisfactory Insufficient

No response

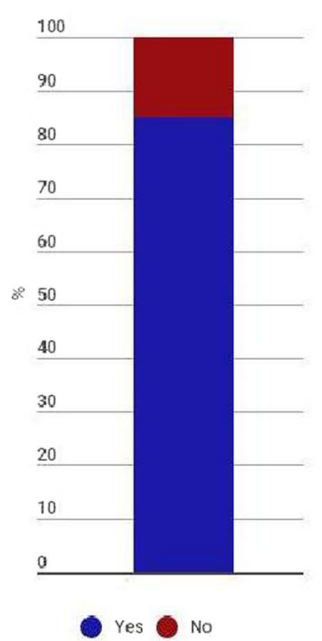

Fig. 2 (See legend on next page.) 
(See figure on previous page.)

Fig. 2 Proportional distribution of responses to questions on final course, 2009, 2011, 2012, 2013 and 2014. Legend: Question A: Was this you first online course?; Question B: Would you take another distance learning course coordinated by the Unifesp Infectious Diseases Division?; Question C: How important do you think it is to include the topic of the rational use of antimicrobial agents in the curriculum of a medical school?; Question D: Overall, how satisfied are you with the course?; Question E: What is your opinion about the content of the course?; Question F: On average, how many hours did you dedicate to the course, including online and offline studies?; Question G: How much do you think you have learned in this course?; Question H: How would you categorise the level of your participation in the course?; Question I: If you had had more time, do you think you could have dedicated yourself more to this course?

stated by Groenwold et al. [21], it is also necessary to allow students the freedom to manage their own curricular and extra-curricular activities in a competent manner. That equation can be tenuous and needs to be individualised, the course tutelage program playing a role in improving student achievement.

This study has some limitations. First, the questionnaires employed in the initial and final assessments were not standardised across the years evaluated. The study design could also be considered a limitation, because there was no control group or randomisation. The timing of the course within the medical education curriculum is also another possible point of distortion in the results: offering the course to sixth-year, rather than fifth-year, medical students could have yielded results that were worse (given that sixth-year students are more intently focussed on their curricular activities and on studying for the residency examination) or better (because sixth-year students ostensibly possess more knowledge than do fifth-year students and can use the course as a form of study for the residency examination). Another limitation of the study is the fact that, in the faceto-face assessments, we used questions that were quite similar to those employed in the evaluations of the VLE. Finally, it should be noted that, in the analyses of the questions assessing previous knowledge, course participation and perceptions of the course, statistical calculations were not always carried out.

An interesting topic for discussion is whether distance learning can replace the traditional methodology. The positive results we obtained for knowledge gain, together with the varied perceptions of the students, allow us to conclude that the DLE is not a replacement for the traditional strategy but can be adopted as a complement, and that instructors should shift the focus toward one or the other depending on the level of development, cognitive gain and preferences of the students, as well as on how the students deal with new technologies. Studies comparing distance learning and traditional methodologies have produced conflicting results, some favouring distance learning $[21,22]$ and others indicating that the two are equivalent [23-25], as in the systematic review recently conducted by Ahmadi et al. [25] However, there are important subjective aspects that are not evaluated in that type of comparison. To elucidate this issue, studies that evaluate it in a more objective manner are needed.

Another important question is whether and to what degree a distance learning methodology can have a positive influence on antimicrobial prescription practices when the student becomes a physician and begins to practice medicine. Unfortunately, the basic guidelines for the proper use of antimicrobial agents, measures for the prevention of nosocomial infection and antimicrobial resistance are not part of the pedagogical plan at most medical schools. In general, medical school curricula are heavily loaded with content and concepts, leaving no space to introduce fundamental concepts related to the proper prescription of antimicrobial agents, which is important regardless of which specialty the students choose in the future. Extra-curricular activities within a DLE could help medical schools bridge that gap.

The U.S. Centers for Disease Control and Prevention (CDC) recommends some core elements of antimicrobial stewardship, one of which is "education" [26]. In their joint guidelines on the implementation of an antibiotic stewardship program [27], the Infectious Diseases Society of America and the Society for Healthcare Epidemiology of America advocated for teaching hospitals to integrate the fundamental principles of antibiotic stewardship into their curricula. Although the CDC recommendation is related to providing instruction for health professionals, we believe that this core element should be extended to medical school curricula.

Our findings support the assertion that the strategy of offering a VLE-based distance learning course is a valid means of increasing student knowledge about antimicrobial stewardship, as suggested by Fakih et al. [28] Although there are no data in the literature with a high grade of recommendation for the use of distance learning as a strategy for teaching topics within the infectious diseases field to medical students, it is believed that this is attributable to the scarcity of studies on the subject and to the different methodologies employed-a situation described in 2003 by Christante et al. [29] and that seems to persist-and it is therefore difficult to make a uniform assessment. Therefore, the present study represents an important attempt to provide a more scientific basis for the use of this strategy. 


\section{Conclusions}

This study suggests that distance learning can replace the traditional methodology in a complementary way, because there is significant improvement on learning process. The students, overall, approved the method, but should have dedicated more time to the course if they had been able to. New approaches and programmatic contents are necessary to avoid dropout, allowing students the freedom to manage their own curricular and extra-curricular activities in a competent manner. We recommend that initiatives like this be used in order to instruct medical students in how to apply antibiotic stewardship to their activities in teaching hospitals.

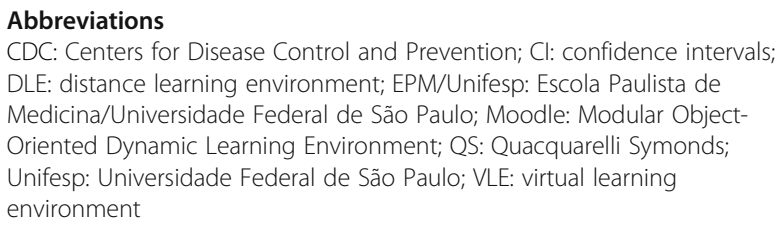

\section{Acknowledgements}

The authors would like to acknowledge all the course participating students.

\section{Authors' contributions}

$\mathrm{ML}$ operationalised the project, interpreted the results and was a major contributor in writing the manuscript. CMG gave substantial contribution to the conception of the course. JLM directed the design of the work and provided analysis and interpretation of data. EAM drafted the work, revised it for important intellectual content and gave the final approval. All authors read and approved the final manuscript.

\section{Funding}

The authors declare that they have no funding during the current study. Whole course was performed free of charge, using the existing infrastructure of EPM/Unifesp.

\section{Availability of data and materials}

The datasets used and analysed during the current study are available from the corresponding author on reasonable request.

\section{Ethics approval and consent to participate}

All participating students gave written informed consent; the study was approved by the Research Ethics Committee of the Hospital São Paulo (Protocol no. 429,036)

\section{Consent for publication}

Not applicable.

\section{Competing interests}

The authors declare that they have no competing interests.

Received: 16 June 2018 Accepted: 22 May 2019

Published online: 07 June 2019

\section{References}

1. Castanho ME. Os métodos ativos e a educação contemporânea. [active methods and contemporary education.] Revista HISTEDBR on-line. 2008; 29:58-67.

2. Amin Z, Boulet JR, Cook DA, Ellaway R, Fahal A, Kneebone $R$, et al. Technology-enabled assessment of health professions education: consensus statement and recommendations from the Ottawa 2010 conference. Med Teach. 2011:33(5):364-9.

3. Hospitalsaopaulo.org.br [homepage on the Internet]. São Paulo: Hospital São Paulo; c2012 [updated 2013 Jan 19; cited 2013 Jan 19]. Available from: http://www.hospitalsaopaulo.org.br/
4. Topuniversities.com [homepage on the Internet]. London: Quacquarelli Symonds (QS) World University Rankings 2017 [updated 2017 Aug 16; cited 2017 Aug 16]. Available from: https://www.topuniversities.com/universityrankings/university-subject-rankings/2017/medicine.

5. Services.folha.com.br [homepage on the Internet]. São Paulo: Ranking Universitário Folha; 2016 [updated 2017 Aug 16; cited 2017 Aug 16]. Available from: https://ruf.folha.uol.com.br/2016/ranking-de-cursos/ medicina/.

6. Timeshighereducation.com [homepage on the Internet]. London: Times Higher Education Latin America Rankings 2017; 2017 [updated 2017 Aug 16; cited 2017 Aug 16]. Available from: https://www. timeshighereducation.com/world-university-rankings/latin-americauniversity-rankings-2017-results-out-now

7. Medeiros EAS, de Andrade Stempliuk V, Santi LQ, Sallas J. Curso medidas de prevenção e controle da resistência microbiana e programa de uso racional de antimicrobianos em serviços de saúde. [course on measures for the prevention and control of antimicrobial resistance and program for the rational use of antimicrobial agents at health care facilities]. São Paulo; 2007.

8. Medeiros EAS, de Andrade Stempliuk V, Santi LQ, Sallas J. Curso uso racional de antimicrobianos Para prescritores. [course on the rational use of antimicrobial agents for prescribers]. São Paulo; 2008.

9. ABED - Associação Brasileira de Educação a Distância. Censo EAD.BR: Relatório Analítico de Aprendizagem a Distância no Brasil 2014 [homepage on the Internet]. Curitiba, Ibpex; 2015 [cited 2016 Feb 25]. Available from: http://www.abed.org.br/censoead2014/CensoEAD2014_portugues.pdf

10. Abbad G, Carvalho RS, Zerbini T. Evasion from internet-based courses: exploring explanatory variables. RAE eletron. 2006;5(2).

11. Weaver MR, Crozier I, Eleku S, Makanga G, Sebuyira LM, Nyakake J, et al. Capacity-building and clinical competence in infectious disease in Uganda: a mixed-design study with pre/post and cluster-randomized trial components. PLoS One. 2012;7(12):e51319.

12. Miyashita T, Iketani $Y$, Nagamine $Y$, Goto T. FaceTime $\left({ }^{\oplus}\right)$ for teaching ultrasound-guided anesthetic procedures in remote place. J Clin Monit Comput. 2014:28(2):211-5

13. Chang LW, Kadam DP, Sangle S, Narayanan S, Borse RT, McKenzie-White J, et al. Evaluation of a multimodal, distance learning HIV management course for clinical care providers in India. J Int Assoc Physicians AIDS Care (Chic). 2012;11(5):277-82

14. Mains EA, Blackmur JP, Dewhurst D, Ward RM, Garden OJ, Wigmore SJ. Study on the feasibility of provision of distance learning programmes in surgery to Malawi. Surgeon. 2011;9(6):322-5.

15. Bagayoko CO, Gagnon MP, Traoré D, Anne A, Traoré AK, Geissbuhler A. Ehealth, another mechanism to recruit and retain healthcare professionals in remote areas: lessons learned from EQUI-ResHuS project in Mali. BMC Med Inform Decis Mak. 2014:14:120

16. Freese KE, Documét $P$, Lawrence JJ, Linkov F, LaPorte RE, Stall RD. Public health education using supercourse: a computer-based learning resource for healthcare professionals in the southern province of Zambia. Public Health Rep. 2014:129(1):100-6.

17. Kulier R, Gülmezoglu AM, Zamora J, Plana MN, Carroli G, Cecatti JG, et al. Effectiveness of a clinically integrated e-learning course in evidence-based medicine for reproductive health training: a randomized trial. JAMA. 2012; 308(21):2218-25.

18. Guerra CM, Ramos MP, Medeiros EA. First Brazilian experience in web-based course for healthcare professionals. Med Teach. 2010;32(2):185.

19. Bollinger RC, McKenzie-White J, Gupta A. Building a global health education network for clinical care and research. The benefits and challenges of distance learning tools. Lessons learned from the Hopkins Center for Clinical Global Health Education. Infect Dis Clin N Am. 2011;25(2):385-98.

20. Premkumar K, Ross AG, Lowe J, Troy C, Bolster C, Reeder B. Technologyenhanced learning of community health in undergraduate medical education. Can J Public Health. 2010;101(2):165-70.

21. Groenwold RH, Knol MJ. Learning styles and preferences for live and distance education: an example of a specialization course in epidemiology. BMC Med Educ. 2013;13:93

22. Worm BS. Learning from simple ebooks, online cases or classroom teaching when acquiring complex knowledge. A randomized controlled trial in respiratory physiology and pulmonology. PLoS One. 2013;8(9):e73336.

23. McGready J, Brookmeyer R. Evaluation of student outcomes in online vs. campus biostatistics education in a graduate school of public health. Prev Med. 2013:56(2):142-4 
24. Peska DN, Lewis KO. Uniform instruction using web-based, asynchronous technology in a geographically distributed clinical clerkship: analysis of osteopathic medical student participation and satisfaction. J Am Osteopath Assoc. 2010:110(3):135-42.

25. Ahmadi SF, Baradaran HR, Ahmadi E. Effectiveness of teaching evidencebased medicine to undergraduate medical students: a BEME systematic review. Med Teach. 2015;37:21-30.

26. CDC. Core Elements of Hospital Antibiotic Stewardship Programs. Atlanta: US Department of Health and Human Services, CDC; 2014. Available at https://www.cdc.gov/antibiotic-use/healthcare/pdfs/core-elements.pdf.

27. Barlam TF, Cosgrove SE, Abbo LM, MacDougall C, Schuetz AN, Septimus EJ, et al. Implementing an antibiotic stewardship program: guidelines by the Infectious Diseases Society of America and the Society for Healthcare Epidemiology of America. Clin Infect Dis. 2016;62(10):e51-77.

28. Fakih MG, Enavet I, Minnick S, Saravolatz LD. A web-based course on infection control for physicians in training: an educational intervention. Infect Control Hosp Epidemiol. 2006;27(7):704-8.

29. Christante L, Ramos MP, Bessa R, Sigulem D. O papel do ensino a distância na educação médica continuada: uma análise crítica. The role of distance learning in continuing medical education: a critical analysis]. Rev Assoc Med Bras. 2003;49(3):326-9.

\section{Publisher's Note}

Springer Nature remains neutral with regard to jurisdictional claims in published maps and institutional affiliations.

Ready to submit your research? Choose BMC and benefit from:

- fast, convenient online submission

- thorough peer review by experienced researchers in your field

- rapid publication on acceptance

- support for research data, including large and complex data types

- gold Open Access which fosters wider collaboration and increased citations

- maximum visibility for your research: over $100 \mathrm{M}$ website views per year

At BMC, research is always in progress.

Learn more biomedcentral.com/submissions 